\title{
Reliability Analysis of Pre-stressed Concrete Continuous Girders Bridge using Incremental Launching Method on Chinese code and AASHTO
}

\section{LRFD}

\author{
Jiangang Cai ${ }^{1,2, a}$, Yue $\mathrm{Xu}^{1, \mathrm{~b}}$, Fenghui Dong ${ }^{3, \mathrm{c}}$ \\ ${ }^{1}$ Department of Bridge Engineering, Chang'an University, Shaanxi Xi'an, China \\ ${ }^{2}$ Zhejiang Provincial Institute of Communications Planning, Design \& Research, Zhejiang \\ Hangzhou, China \\ ${ }^{3}$ Department of Bridge Engineering, Tongji University, Shanghai, China \\ a tonney5312@163.com, byx1958@163.com, nuaadfh@163.com
}

Keywords: Pre-stressed Concrete; Girder Bridge; Incremental Launching Construction; Chinese code; AASHTO LRFD; Reliability.

\begin{abstract}
The object of this paper analyzes the reliability level of pre-stressed concrete continuous girder bridges designed with the Chinese code (JTG D62-2004) and AASHTO LRFD (2007) using incremental launching method at construction stage. Typical cross-sections used in the example bridge are considered at construction stage. Load and resistance parameters are treated as random variables. The statistical parameters are based on the available literature, test data and survey results. Reliability indices are calculated by iterations using the first-order second-moment method. The calculated results indicate that the reliability indices on of JTG D62-2004 are larger that of AASHTO LRFD, which could provide the references for the bridges on the incremental launching construction in overseas construction and competition.
\end{abstract}

\section{Introduction}

Over the last half century, a large number of pre-stressed concrete bridges has been built or are under construction all over the world. The rapid increased number of this kind of bridges is mainly due to their excellent mechanical characteristics and practical advantages in construction. There is an important construction method which should be considered in designing such structures, which is incremental launching method. The incremental launching method for bridge construction may offer advantages over conventional construction, including creating minimal disturbance to surrounding, providing a more concentrated work area for superstructure assembly, and possibly increased worker safety given the improved erection environment.

It is estimated that over 1,000 bridges worldwide have been constructed by the incremental launching method [1], the vast majority of which have been post-tensioned concrete box girder bridges. So far, to the authors' knowledge, the reliability analysis has not been applied to the pre-stressed concrete continuous girder bridges using incremental launching method. This study focuses on analyzing the reliability indices of pre-stressed concrete continuous girder bridges 
designed with the Chinese code (JTG D62-2004) [2] and AASHTO LRFD (2007) [3] using incremental launching method during construction the stage.

\section{Basic Information of the Bridge}

The bridge, which is a double-parallel pre-stressed concrete post-tensioned continuous girder bridge with the span of $30 m+3 \times 40 m+30 m$, is constructed by incremental launching method in the highway, and its total length is $180 \mathrm{~m}$. The length of the center of the side pier and the beam-ends is $0.45 \mathrm{~m}$, in addition, the length of the side span is $29.55 \mathrm{~m}$. The launching nose is $25 \mathrm{~m}$ long and the ratio of it to main span is 5/8. The geometry of girder is shown in Fig.1, in which all dimensions are in centimeters.

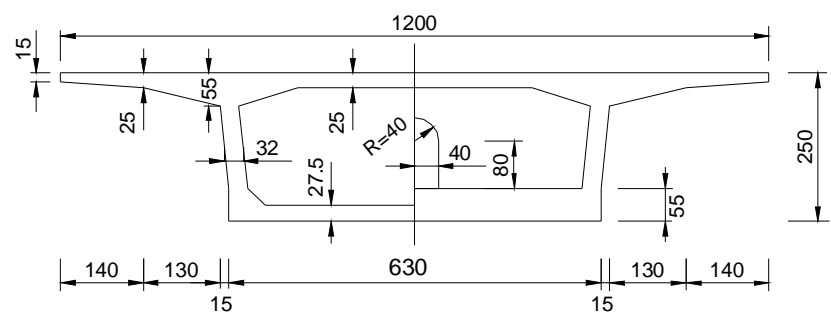

Fig.1 Girder geometry (unit: $\mathrm{cm}$ )

The bridge is calculated by the finite element procedure. The length of calculated side span is 29.55, which is considered as $30 \mathrm{~m}$ briefly. There are 72 elements and 73 nodes in the total bridge. The length of calculated element is $2.5 \mathrm{~m}$, which includes 10 elements and 11 nodes of the launching nose with the length of $25 \mathrm{~m}$. The numbers of nodes and elements of the launching nose are 1 11 and 1 10 respectively, the main girders $11 \sim 83$ and 11 82 respectively as well. The segments of incremental launching are $10 \mathrm{~m}+5 \mathrm{~m}+15 \times 10 \mathrm{~m}+5 \mathrm{~m}+10 \mathrm{~m}$. The nodes and elements in the bridge are shown in Fig.2. The Table.1 indicates the construction stage division.

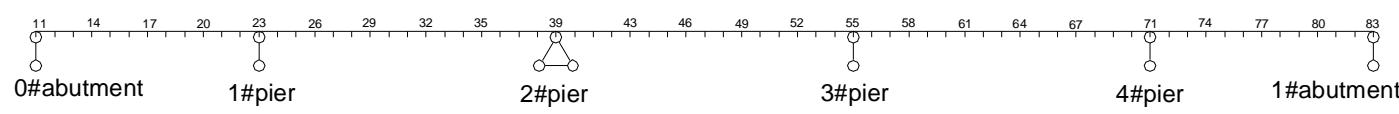

Fig. 2 The elements in the total bridge

Table. 1 The construction stage division

\begin{tabular}{ccc}
\hline $\begin{array}{c}\text { Number of } \\
\text { construction stage }\end{array}$ & $\begin{array}{c}\text { Installing of } \\
\text { elements }\end{array}$ & construction illustration \\
\hline 1 & $1 \sim 14$ & Casting NO.1 segment-10m \\
2 & $15 \sim 16$ & Casting NO.2 segment-5m \\
3 & $17 \sim 20$ & Casting NO.3 segment-10m \\
17 & $73 \sim 76$ & Casting NO.17 segment-10m \\
18 & $77 \sim 78$ & Casting NO.18 segment-5m \\
19 & $79 \sim 82$ & Casting NO.19 segment-10m \\
20 & & Temperature piers removed \\
21 & $1 \sim 10$ deleted & The launching nose removed \\
22 & & 2nd Pre-stressed tendons were drawn \\
23 & & Deck pavement and attached facilities \\
\hline
\end{tabular}




\section{Load model}

The major load components for highway bridges are dead load, live load, dynamic load, environment loads (temperature, wind, earthquake), and other loads (collision, braking). In this study, only the first load and pre-stressing are considered, the load models are based on the available statistical data, surveys, inspection reports, and analytical simulations. The load variation is described by cumulative distribution function (CDF), mean value or bias factor (ration of mean to nominal value), and coefficient of variation.

Dead load is the gravity load due to the self weight of structural and non structural elements (prestressing force in this study) permanently connected to the bridge. Two components are considered: $\mathrm{D}_{1}=$ dead load due to cast-in-place materials (bridge girder), and $\mathrm{D}_{2}=$ dead load due to asphalt overlay. All components of dead load are typically treated as normal random variables. The bias factor (ratio of mean to nominal), $\lambda=1.03$, and coefficient of variation, $V=0.08$, for $D_{1}$, and $\lambda=1.05$ and $V=0.10$ for $D_{2}$ [4]. For asphalt wearing surface it is assumed that mean thickness is 80 $\mathrm{mm}$.

In concrete structures, pre-stressed effects are generally considered as a force being applied to the structure. A pre-stressed force $P(x, t)$ at a distance of $x$ from the anchorage at time $t$ may be expressed by the following [5]:

$$
P(x, t)=P_{0}-\Delta P(x, t)
$$

where $P_{0}, \Delta P(x, t)$ are the initial pre-stressed force and the pre-stressed losses, respectively. JCSS [5] proposes that we retain the value given by the standard or regulation as a mean value for the losses, and to take those found in Table. 2 as coefficients of variation.

Table. 2 Coefficient of variation for pre-stressed losses and pre-stressed force

\begin{tabular}{cccc}
\hline Parameter & Mean value & \multicolumn{2}{c}{ Variation coefficient } \\
\cline { 3 - 4 } Pre-stressed losses $\Delta P(x, t)$ & 1 & 0.3 & $t=\infty$ \\
Pre-stressed force $P(x, t)$ & 1 & 0.04 & 0.3 \\
\hline
\end{tabular}

\section{Resistance model}

Resistance is a variable representing the load carrying capacity. The type of distribution is based on observed shape of CDFs for presenting steel and concrete. Resistance is considered as a product of three factors representing strength of materials, dimensions and analysis. The stress of cross section is considered to calculate the reliability index at the construction stage according the codes of JTG D62-2004 and AASHTO LRFD. According to calculating results, the stresses of all cross sections in the bridge are compressive stresses.

According the JTG D62-2004, the compressive stress $\sigma_{c c}^{t}$ in the construction stage must meet the following minimum requirements:

$$
\sigma_{c c}^{t} \leq 0.70 f_{c k}^{\prime}
$$

In this formula, $f_{c k}^{\prime}$ is the standard value of the compressive strength of concrete at the center of the axis at various stages of manufacture, transportation and hoisting.

According the AASHTO LRFD, the compressive stress $\sigma_{c c}^{t}$ in the construction stage must meet the following minimum requirements:

$$
\sigma_{c c}^{t} \leq 0.55 f_{c}^{\prime}
$$


In this formula, $f_{\mathrm{c}}^{\prime}$ is the specified compressive strength of concrete for use in design.

The resistance model statistics of the codes for JTG D62-2004 and AASHTO LRFD are shown in Table.3.

Table.3 The resistance model statistics of JTG D62-2004 and AASHTO LRFD

\begin{tabular}{cccccc}
\hline Specifications & $\begin{array}{c}\text { Probabilistic } \\
\text { distribution }\end{array}$ & $\begin{array}{c}\text { Compressive } \\
\text { strength }\end{array}$ & $\begin{array}{c}\text { Mean } \\
\text { value }\end{array}$ & $\begin{array}{c}\text { Variation } \\
\text { coefficient }\end{array}$ & Ref. \\
\hline JTG D62-2004 & Normal distribution & $32.4 \mathrm{MPa}(\mathrm{C} 50)$ & 1.3877 & 0.1374 & {$[12]$} \\
AASHTO LRFD & Normal distribution & $32.4 \mathrm{Mpa}(\mathrm{C} 50)$ & 1.38 & 0.12 & {$[13]$} \\
\hline
\end{tabular}

\section{Reliability analysis}

Reliability analysis is performed for pre-stressed concrete bridge girders designed according to the considered codes. The reliability index, $\beta$, is defined as a function of probability of failure, $P_{F}$,

$$
\beta=-\Phi^{-}\left(P_{F}\right)
$$

where, $\Phi^{-1}$ is inverse standard normal distribution function. An iterative procedure is used calculate the reliability index as described by Ming Zhang [14].

Due to the force at the construction stage of the pre-stressed concrete continuous girder bridge using incremental launching construction, two cross sections, which include the maximum moment and the minimum moment, were chosen according to the bending moment diagrams of the construction stage to calculate the reliability index.

The Figure. 3 shows the bending moment diagram of the cross section in the construction stage according to the code of JTG D62-2004, from which the NO.17 is the minimum moment value $(-30470.4 \mathrm{kN} \cdot \mathrm{m})$ and the NO.16 is the maximum moment value $(18754.76 \mathrm{kN} \cdot \mathrm{m})$. As shown in Figure.3, the cross section of NO.16 and NO.17 were chosen to calculate and analyze the reliability index in the construction stage.

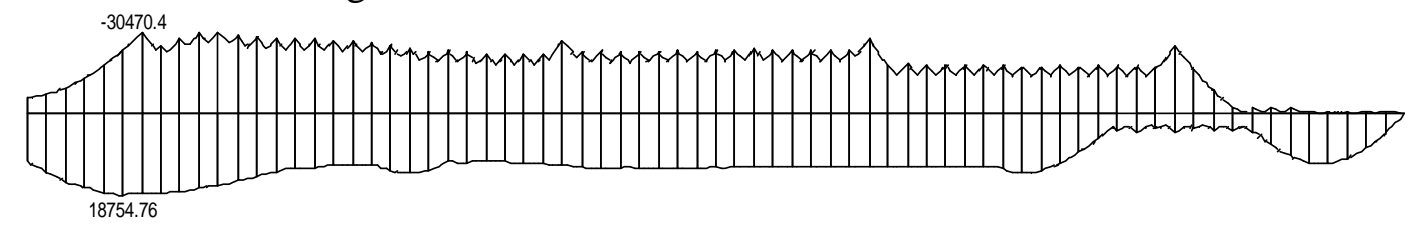

Figure. 3 The bending moment diagram of in the construction stage

As for the construction stage, the reliability index of both upper and bottom flange of cross section NO.16 and NO.17 are shown in Figure.4 Figure.7 according to the codes of JTG D62-2004 and AASHTO LRFD. In addition, the Table. 4 shows the average reliability index of the cross section NO.16 and NO.17 with the construction stage. 


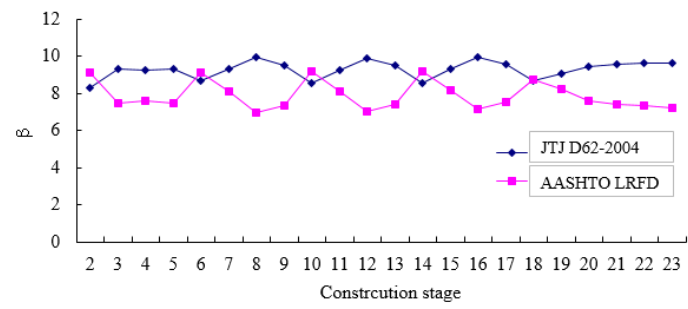

Figure.4 The upper flange reliability index of the cross section of NO.16

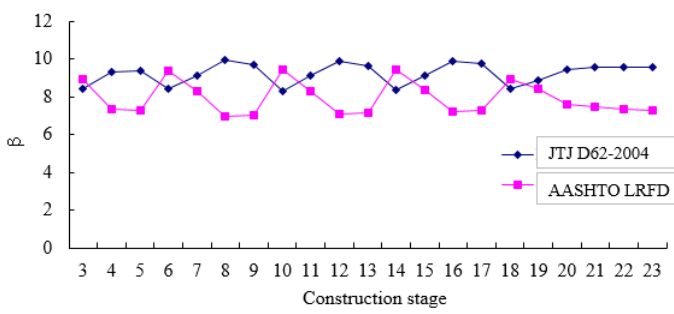

Figure.6 The upper flange reliability index of the cross section of NO.17

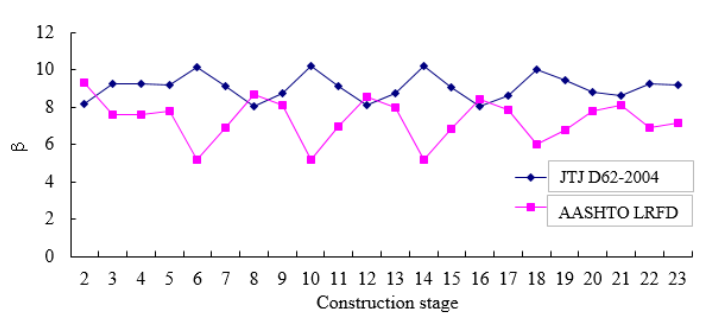

Figure. 5 The bottom flange reliability index of the cross section of NO.16

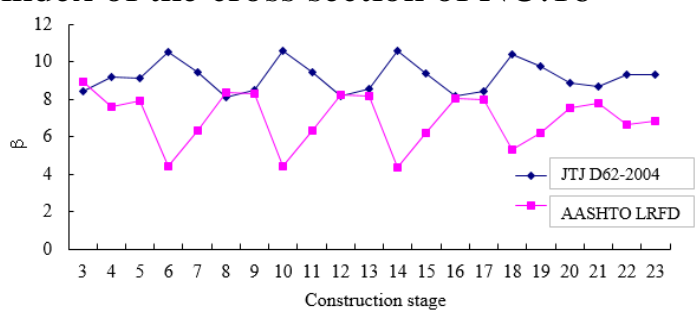

Figure.7 The bottom flange reliability index of the cross section of NO.17

Table. 4 The average reliability of cross section of NO.16 and NO.17 in the construction

\begin{tabular}{cccccccc}
\hline \multicolumn{3}{c}{ Cross section of NO.16 } & \multicolumn{3}{c}{ Cross section of NO.17 } \\
\hline \multicolumn{2}{c}{ Upper flange } & \multicolumn{2}{c}{ Bottom flange } & \multicolumn{2}{c}{ Upper flange } & \multicolumn{2}{c}{ Bottom flange } \\
\hline JTG & LRFD & JTG & LRFD & JTG & LRFD & JTG & LRFD \\
\hline 9.27 & 8.62 & 9.05 & 8.53 & 9.22 & 8.77 & 9.18 & 8.82 \\
\hline
\end{tabular}

\section{Conclusions}

The reliability analysis is performed for pre-stressed concrete bridge girders designed on the incremental launching construction according to two codes: the code of JTG D62-2004 and AASHTO LRFD. The load and resistance parameters are treated as random variables, and the statistical parameters are taken from the available literature, test data and survey results. Subject to the limitations of the assumptions and parameters in the study, the following conclusions can be obtained:

(1) The calculated reliability indices vary considerably on the construction stage for the two considered codes.

(2) At the construction stage, generally, the calculated reliability indices results in the code of JTG D62-2004 are larger than that of AASHTO LRFD.

\section{References}

[1] Gohler, Bernhard and Pearson, P., Incrementally Launched Bridges Design and Construction, Ernst and Sohn, Berlin(2000)

[2]The Code for Design of Highway Reinforced Concrete and Pre-stressed Concrete Bridges and Culverts of JTG D62-2004. Beijing: People's Communication Press. (2004) ( In Chinese ) 
[3] American Association of State Highway and Transportation Officials. AASHTO LRFD Bridge Design Specifications[S], Washington, DC, 2007

[4] Nowak AS. Calibration of LRFD bridge code. ASCE J Struct Eng 121(8):1245-51. (1995)

[5] JCSS, JOINT COMMITTEE ON STRUCTURAL SAFETY, Probabilistic model code (2001)

[6] Li Yanghai, Bao Weigang, Guo Xiuwu, Cheng Xiangyun. Reliability and Probability Limit State Design of Highway Bridge Structure. Beijing: China Communications Press. (1997) ( In Chinese )

[7] Christian Cremona. Structural Performance Probability-based Assessment. Wiley. (2011)

[8] Ming Zhang. Structure Reliability Analysis-method and Procedures. Beijing: Science Press.(2009) ( In Chinese ) 